\title{
Morfometria de frutos, sementes e plântulas e métodos para superação da dormência de sementes de Guazuma ulmifolia Lam. (Malvaceae)
}

Morphometry of fruits, seeds and seedlings and methods for overcoming dormancy in seeds of Guazuma ulmifolia Lam. (Malvaceae)

Morfometría de frutos, semillas y plátulos y métodos para superar el dormir en semillas de Guazuma ulmifolia Lam. (Malvaceae)

\section{Resumo}

O presente estudo objetivou analisar a morfometria de frutos, sementes e plântulas de Guazuma ulmifolia Lam., além de testar diferentes modalidades de tratamentos para superar a dormência de suas sementes. Inicialmente foi realizada a biometria de frutos e sementes e, posteriormente, de plântulas. Os tratamentos utilizados para quebra da dormência foram: testemunha (T1); escarificação química com ácido sulfúrico (H2SO4) 98\% por 5 min (T2), 15 min (T3), 30 min (T4) e 50 min (T5); escarificação química com ácido sulfônico (H-S(=O)2-OH) por 50 min (T6) e 60 min (T7); escarificação química com ácido muriático $(\mathrm{HCl})$ por $60 \mathrm{~min}(\mathrm{~T} 8)$ e; imersão em água quente (T9) a $90^{\circ} \mathrm{C}$ por 10 min. Depois de submetidas aos tratamentos, as sementes foram semeadas em folhas de papel germitest. Avaliou-se a porcentagem de germinação $(\% \mathrm{G})$, o índice de velocidade de germinação (IVE) e o tempo médio de germinação (TME). O delineamento experimental utilizado foi inteiramente ao acaso. Os dados foram submetidos à análise de variância e a comparação entre as médias realizadas através do teste de Tukey a $5 \%$ de significância. Somente o tratamento de imersão em água quente a $90^{\circ} \mathrm{C}$ por $10 \mathrm{~min}$ foi eficiente para superar a dormência em sementes de $G$. ulmifolia, proporcionando $68 \%$ de germinação. Os demais tratamentos não aumentaram significativamente a germinação, igualando-se à testemunha. Para a análise de variância do TME, não foram observadas diferença significativa entre os tratamentos realizados.

Palavras-chave: Biometria vegetal; Germinação; Mutamba.

\begin{abstract}
The present study aimed to analyze the morphometry of fruits, seeds and seedlings of Guazuma ulmifolia Lam., In addition to testing different treatment modalities to overcome the dormancy of its seeds. Initially, the biometry of fruits and seeds and, later, seedlings were performed. The treatments used for breaking dormancy were: control (T1); chemical scarification with sulfuric acid (H2SO4) 98\% for $5 \mathrm{~min}$ (T2), $15 \mathrm{~min}$ (T3), $30 \mathrm{~min}$ (T4) and $50 \mathrm{~min}$ (T5); chemical scarification with sulfonic acid $(\mathrm{H}-\mathrm{S}(=\mathrm{O}) 2-\mathrm{OH})$ for $50 \mathrm{~min}(\mathrm{~T} 6)$ and $60 \mathrm{~min}(\mathrm{~T} 7)$; chemical scarification with muriatic acid $(\mathrm{HCl})$ for $60 \mathrm{~min}(\mathrm{~T} 8)$ and; immersion in hot water (T9) at $90{ }^{\circ} \mathrm{C}$ for $10 \mathrm{~min}$. After undergoing the treatments, the seeds were sown on sheets of germitest paper. The germination percentage (\% G), the germination speed index (IVE) and the average germination time (TME) were evaluated. The experimental design used was entirely random. The data were subjected to analysis of variance and the comparison between the averages performed
\end{abstract}


using the Tukey test at $5 \%$ significance. Only the immersion treatment in hot water at $90^{\circ} \mathrm{C}$ for 10 min was efficient to overcome dormancy in G. ulmifolia seeds, providing $68 \%$ germination. The other treatments did not significantly increase germination, being equal to the control. For the analysis of variance of the TME, it was observed that there was no significant difference in any of the treatments.

Keywords: Plant biometrics; Germination; "Mutamba".

\section{Resumen}

El presente estudio tuvo como objetivo analizar la morfometría de frutos, semillas y plántulas de Guazuma ulmifolia Lam., Además de probar diferentes modalidades de tratamiento para superar la latencia de sus semillas. Inicialmente se realizó la biometría de frutos y semillas y, posteriormente, plántulas. Los tratamientos utilizados para romper la latencia fueron: control (T1); escarificación química con ácido sulfúrico (H2SO4) 98\% durante 5 min (T2), 15 min (T3), 30 min (T4) y 50 min (T5); escarificación química con ácido sulfónico (H-S (= O) 2-OH) durante 50 min (T6) y $60 \mathrm{~min}(\mathrm{~T} 7)$; escarificación química con ácido muriático $(\mathrm{HCl})$ durante $60 \mathrm{~min}(\mathrm{~T} 8)$ y; inmersión en agua caliente (T9) a $90^{\circ} \mathrm{C}$ durante 10 min. Después de someterse a los tratamientos, las semillas se sembraron en hojas de papel más germinado. Se evaluó el porcentaje de germinación (\% G), el índice de velocidad de germinación (IVE) y el tiempo promedio de germinación (TME). El diseño experimental utilizado fue completamente aleatorio. Los datos se sometieron a análisis de varianza y la comparación entre los promedios se realizó mediante la prueba de Tukey al $5 \%$ de significancia. Solo el tratamiento de inmersión en agua caliente a $90^{\circ} \mathrm{C}$ durante 10 min fue eficaz para superar la latencia en semillas de G. ulmifolia, proporcionando un $68 \%$ de germinación. Los otros tratamientos no incrementaron significativamente la germinación, siendo igual al testigo. Para el análisis de varianza de la TME, se observó que no hubo diferencia significativa en ninguno de los tratamientos.

Palabras clave: Biometría vegetal; Germinación; Mutamba.

\section{Introdução}

Guazuma ulmifolia Lam. é popularmente conhecida como mutambo, mutamba, fruto do macaco, embira, embireira e verdadeira mutamba. Pertence à família Malvaceae, a qual compreende 250 gêneros de distribuição pantropical, sendo comum no cerrado, mas também da Amazônia ao Paraná (Souza \& Lorenzi, 2019) e, segundo Barbosa e Macedo (1993) em toda a América Latina. No estado do Piauí, há registro desta espécie em área de transição cerrado-caatinga (Araújo, Lima \& Lemos, 2019).

As espécies vegetais nativas vêm diminuindo constantemente no meio ambiente, tal fato está relacionado diretamente com a comercialização realizada pelo homem, que ao reduzir os recursos disponibilizados no ambiente não se preocupam com o reflorestamento ambiental. Além disso, a propagação destas espécies é, muitas vezes, limitada pela ocorrência de dormência nas sementes, dificultando a sua germinação e, consequentemente, retardando a recuperação da floresta de forma natural. Diferente das espécies agrícolas, as sementes de espécies florestais apresentam dificuldade quanto a padronização de técnicas e condições adequadas para a condução do teste de germinação (Figliolia, 2015).

Estudos morfológicos têm grande importância pelo fato do seu conhecimento servir como alicerce na identificação de espécies, além de serem úteis para a identificação, podem auxiliar em estudos envolvendo a avaliação de regeneração natural dos ecossistemas, formas de manejo e definição de estratégias para a conservação das espécies e desenvolvimento de técnicas eficientes na produção de mudas (Batista, Costa, Gimenes, Pivetta \& Môro, 2011). Segundo Soares, Nogueira, Grabias e Kuniyoshi (2017), estudos com base nas características de uma espécie frequentemente são restritos devido à falta da identificação taxonômica correta. Bewley, Bradford e Hilhorst (2013), afirmam, inclusive, que as características morfológicas são diferentes entre classes, famílias e espécies de plantas, visto que se observa diferenças nos tecidos de reservas e formas de tegumento, mesmo havendo mecanismos de desenvolvimento comuns entre espécies.

A morfologia de frutos e sementes é de extrema importância para a diferenciação das espécies em campo, principalmente em trabalhos de coleta de espécies específicas para produção de mudas, com o intuito de recuperação de áreas degradadas (Sampaio et al., 2015). Os aspectos morfológicos, assim como a coloração e o tamanho, podem influenciar diretamente na germinação, uma vez que são primordiais para o processo de identificação e diferenciação das espécies (Bílio, 2018). 
A biometria da semente está relacionada principalmente às características de dispersão e estabelecimento de plântulas, sendo o peso específico e o tamanho das sementes, indicativos de sua qualidade fisiológica (Carvalho \& Nakagawa, 2012). Embora sejam características influenciadas diretamente pelo clima, fertilidade do solo, maturidade das sementes e sanidade, é possível observar variações em tamanho e desempenho das sementes durante uma estação de produção (Marcos-Filho, 2015). Espécies como Chloroleucon tenuiflorum (Benth.) Barneby and J.W.Grimes (Zapater et al., 2016), Poincianella pyramidalis (Tul.) L. P. Queiroz (Mendonça, Freitas, Souza, Fonseca \& Souza, 2016), Sarcaulus brasiliensis A. DC. Eyma (Silva, Gurgel, Cruz \& Santos, 2016), Apuleia molaris Spruce ex Beth. (Reis, Freitas, Leão \& Santos Filho, 2016), Palicourea racemosa (Aubl.) Borhidi (Silva, Bispo, Pedri, Lopes \& Rossi, 2017), Parkia pendula (Willd.) Benth. ex Walp. (Santana, Silva, Morangon \& Feliciano, 2018), Physocalymma scaberrimum Pohl (Oliveira, Filho, Sousa \& Cruz, 2018), Tachigali guianensis (Benth.) (Leão, Shimizu, Felipe \& Benchimol, 2018) e Canavalia dictyota Piper (Silva, Teixeira, Mendes, Lemos \& Freitas, 2019) são exemplos com os quais foram realizados estudos recentes relacionados a aspectos morfológicos.

A germinação das sementes é caracterizada por um conjunto de processos de transformação, os quais poderá originar uma nova planta. São sucessões de etapas que estão associadas ao crescimento do embrião, de maneira que são necessárias trocas líquidas e gasosas entre o meio e a semente (Fernandes et al., 2018). Todavia, é importante destacar que alguns fatores ambientais como luz, temperatura, água, nutrientes, fauna e microrganismos são essenciais e para a ocorrência da germinação e superação de dormência (Ramos ,2015). Dentre todos os fatores, a água é considerada um dos principais no que diz respeito ao processo de germinação, e a ocorrência da reidratação dos tecidos, verifica-se a intensificação da respiração e de todas as outras atividades metabólicas da semente (Mews, Silvério, Mews, Cury \& Santos, 2012).

Para iniciar o processo de germinação é necessário haver uma ruptura na camada impermeável. Isto pode ser feito artificialmente, por escarificação mecânica ou com substâncias químicas corrosivas, como ácidos. Diversos estudos com escarificação química para superar a dormência de espécies florestais foram realizados por diversos autores, tais como Mendes, Costa, Lima, Carvalho e Reis (2016), com Hymenaea parvifolia Huber.; Gonçalves, Carvalho e Cabacinha (2017) com Stryphnodendron adstringens (Mart.) Coville.; Naves, Rezende, Alcantra e Rezende (2018) com Ormosia arborea e Candido e Oliveira (2018) com Schizolobium parahyba (Vellozo) S. F. Por exemplo, a aplicação de ácido promove a quebra da dormência em sementes de Stylosanthes humilis (Kunth) Herter (Chaves, Silva \& Ribeiro, 2017).

Além da possibilidade mencionada anteriormente, a imersão em água quente a uma determinada temperatura, para algumas espécies, pode ser utilizada como método para a superação de dormência, como verificado para sementes de Ochroma pyramidale (Cav.) Urb. (Santos, Deuner, Meneghello, Almeida \& Xavier, 2016) e Passiflora actinia Hooker. (Grzybowski, Silva, Belniaki \& Panobianco, 2019).

No contexto deste quadro, o presente estudo objetivou analisar a morfometria de frutos, sementes e plântulas, além de testar diferentes tratamentos para superar a dormência de sementes de Guazuma ulmifolia Lam.

\section{Metodologia}

Este trabalho, além de etapas laboratoriais, lida com material coletado em campo, tendo, no geral, perfil qualiquantitativo, seguindo o proposto por Pereira, Shitsuka, Pereira e Shitsuka (2018). Assim, além de análise numérica de dados, explora características morfofisiológicas que caracterizam o táxon objeto deste estudo.

\subsection{Local de coleta}

Os frutos foram colhidos, de diferentes matrizes, no mês de novembro de 2019, na localidade Salgado $\left(03^{\circ} 16^{\prime} 55.8^{\prime \prime} \mathrm{S}\right.$ 41 54'34.4" O), situada no município de Buriti dos Lopes, localizado a $50 \mathrm{~km}$ da cidade de Parnaíba, norte do Piauí. O local tem vegetação com morfofisiológicos de caatinga, onde perdem suas folhas na estação de seca. Apresentando flora com vários 
elementos caducifólios nos quais representam uma adaptação fisiológica estratégica para sobrevivências das espécies a falta de água (Pernambuco, 2013).

\subsection{Local de realização do experimento e Beneficiamento}

O experimento foi conduzido no Laboratório de Ciências da Universidade Estadual do Piauí-UESPI/Campus Prof. Alexandre Alves de Oliveira. Inicialmente, realizou-se a seleção dos frutos, descartando aqueles que apresentavam deformação e sinais de ataque de insetos. Posteriormente, as sementes foram extraídas, manualmente, dos frutos e beneficiadas. Durante o beneficiamento, foram separadas e excluídas do lote as sementes malformadas e danificadas por fungos e insetos e, após esta etapa as mesmas foram desinfetadas com hipoclorito de sódio.

\subsection{Biometria de frutos e sementes}

Para a descrição da morfologia externa dos frutos e das sementes foram utilizados 100 frutos e 100 sementes, escolhidas aleatoriamente. Nos frutos foram observados: tipo, coloração, dimensão, textura, deiscência e número de sementes por fruto. Nas sementes, as características morfológicas externas observadas foram: forma, coloração e textura.

A classificação dos frutos e sementes foi baseada nas variáveis: comprimento, largura e massa, e classificação das plântulas apenas a variável comprimento. Para mensuração de comprimento e largura dos frutos, sementes e plântulas foi utilizado um paquímetro digital com precisão de $0,01 \mathrm{~mm}$, sendo o comprimento considerado da base até o ápice e a largura obtida na parte mediana dos frutos e sementes, para as plântulas foi considerado somente a superfície da raiz durante todo o período de seu desenvolvimento.

Amassa foi aferida utilizando-se uma balança analítica com precisão de 0,0001 g. Os dados das variáveis frutos e sementes foram submetidos à análise descritiva, obtendo-se as médias, valor máximo e mínimo, Desvio Padrão-DP e Coeficiente de Variação-CV (Banzatto \& Kronka, 1992) e a frequência relativa, de acordo com Labouriau e Valadares (1976).

Inicialmente foi determinado o grau de umidade das sementes, foram utilizadas duas repetições com 25 sementes por tratamento, sob temperatura de $105^{\circ} \mathrm{C} \pm 3^{\circ} \mathrm{C}$ durante 24 horas. Os resultados foram expressos em porcentagem com base no peso das sementes ainda úmidas (Brasil, 1992). Foi determinado ainda o peso de mil sementes por meio da separação manual de oito sub amostras, contendo 100 sementes para cada lote, onde foi aferida a média das amostras e multiplicado por 1000 e dividido pelo número total de sementes para determinação do peso, conforme metodologia proposta por Brasil (2009). Foram determinados também o número de sementes por fruto e a quantidade de sementes por quilo. Posteriormente, as sementes foram dispostas em sacos plásticos e armazenadas em geladeira até a instalação do experimento.

\subsection{Superação da dormência}

Os tratamentos utilizados para superação da dormência foram: Testemunha (T1) - sem nenhum tratamento, sementes intactas; Escarificação química com ácido sulfúrico (H2SO4) - as sementes foram imersas em ácido sulfúrico na concentração 98\% por 5 min (T2), 15 min (T3), 30 min (T4) e 50 min (T5); Escarificação química com ácido sulfônico (H-S(=O)2-OH) - as sementes foram imersas em ácido sulfônico por 50 min (T6) e 60 min (T7); Escarificação química com ácido muriático (HCl) - as sementes foram imersas em ácido muriático por $60 \mathrm{~min}$ (T8); Imersão em água quente (T9) -foi realizada a imersão das sementes em água à temperatura de $90{ }^{\circ} \mathrm{C}$ por $10 \mathrm{~min}$, e retiradas após o equilíbrio da temperatura com o ambiente.

Para a realização do tratamento de escarificação química com ácido, as sementes foram separadas para cada tempo de exposição, as quais foram colocadas em béquer, acrescentando ácido até cobri-las, revolvendo-se constantemente com um bastão de vidro, objetivando uniformizar a ação abrasiva em diferentes períodos de imersão. Após o tempo de imersão determinado para cada tratamento, as sementes foram retiradas do béquer, colocadas em uma peneira metálica e lavadas em 
água corrente por aproximadamente 10 minutos para que o ácido fosse totalmente retirado. Após implementar os tratamentos, as sementes foram semeadas em folhas de papel germitest na forma de rolos, previamente umedecidos na proporção de 2,5 vezes a massa (g) seca do substrato.

\subsection{Parâmetros avaliados}

As avaliações das plântulas foram realizadas diariamente conforme estabelecido pelas Regras para Análise de Sementes (Brasil, 2009). Foram avaliadas as seguintes características: (\%G) - Percentual de Emergência - foram utilizadas 100 sementes por tratamento, divididas em quatro sub amostras de 25 sementes. A contagem do número de sementes germinadas iniciou-se no segundo dia e estendeu-se até o décimo dia após a semeadura. Foram consideradas germinadas as sementes que apresentaram a protrusão da radícula e calculado através da equação de Labouriau e Valadares (1976): \%G = (N/NS)*100 (onde: N- número de sementes germinadas ao final do teste e NS - número de semente colocada para germinar);(IVE) - Índice de Velocidade de Emergência - foram realizadas contagens diárias, durante 10 dias, das plântulas normais, sendo o índice calculado conforme a fórmula proposta por Maguire (1962): IVG $=\sum(\mathrm{Ni} / \mathrm{Di})$ (onde: $\mathrm{N} 1, \mathrm{~N} 2 \ldots \mathrm{Ni}=$ número de sementes germinadas na primeira contagem, segunda contagem... i-ésima contagem, respectivamente; D1 , D2... Di = número de dias na primeira contagem, segunda contagem... i-ésima contagem, respectivamente); (TME) -Tempo Médio de EmergênciaCorresponde ao número de sementes germinadas por dia multiplicado pelo tempo de incubação dividido pelo tempo de incubação, calculado através da equação de Labouriau (1983): TMG $=(\Sigma$ niti) $/ \Sigma$ ni, em que, ni $=$ número de sementes germinadas por dia; $\mathrm{ti}=$ tempo de incubação (dias).

\subsection{Delineamento experimental}

O delineamento experimental utilizado foi o inteiramente ao acaso, constando de nove tratamentos. Os dados foram submetidos a análises de variância e a comparação entre as médias realizada através do teste de Tukey a 5\% de significância. O processamento dos dados foi realizado com o software estatístico SISVAR (Ferreira, 2000).

\section{Resultados e discussão}

\subsection{Biometria de frutos e sementes}

Os frutos são do tipo seco, com forma globosa e projeções pontiagudas, de cor escura tendendo à tonalidade preta, com cinco fendas com superfície muricada (Figura 1). As sementes são pequenas, de cor ligeiramente acinzentada e com aspecto morfológico variável, sendo arredondadas ou achatadas, quando umedecidas apresentam cor mais escura e formam uma substância gelatinosa transparente ao redor da semente. Estas características são concordantes com as já descritas por Sobrinho e Siqueira (2008), quando estudaram Guazuma ulmifolia Lam. na região do município de Porangatu, Goiás, área com vegetação de cerrado. 
Figura 1. Morfologia externa de frutos e sementes de Guazuma ulmifolia Lam., Parnaíba, Piauí.

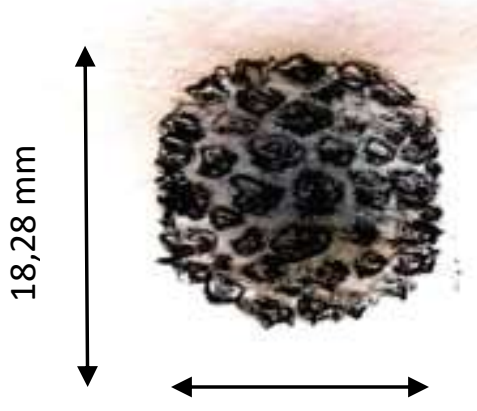

$17.51 \mathrm{~mm}$

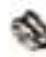

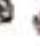

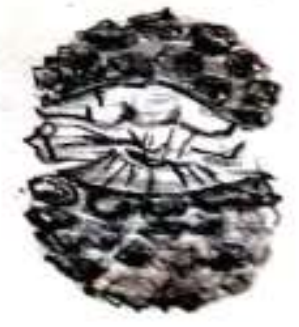

Fonte: Autores.

Observa-se que o comprimento dos frutos de Guazuma ulmifolia Lam. variou de 14,95 a 19,39 mm, enquanto a largura apresentou valores de 15,75 a 21,43 mm. Já para as sementes, o comprimento variou de 2,02 a 2,90 mm e a largura variou de 1,36 a 1,97 mm. A massa dos frutos e sementes varia entre 1,33 a 3,24 e 0,0043 a 0,0052 g, respectivamente (Tabela 1). Os valores referentes à biometria das sementes são divergentes aos encontrados por Carvalho (2007) quando as caracterizou, em seu estudo taxonômico da espécie, com um comprimento entre $3 \mathrm{~mm}$ e $5 \mathrm{~mm}$. Em contrapartida, são compatíveis com os de Lorenzi (2016) que as caracteriza com tamanhos entre $2 \mathrm{~mm}$ e $3 \mathrm{~mm}$.

De acordo com os resultados, pode-se constatar que as sementes de Guazuma ulmifolia apresentam variação pequena quanto ao seu tamanho. Já em relação aos frutos, obteve-se uma maior variação, observando-se quantidade expressiva de sementes por fruto em frutos maiores (em média 63 sementes). Tais resultados, são contrários aos verificados por Lorenzi (2016), onde observaram média de 160 sementes por fruto. Segundo Silva e al. (2017), a diferença no tamanho das sementes dentro de uma mesma espécie está associada ao ambiente onde a planta se encontra.

Tabela 1. Biometria dos frutos e sementes de Guazuma ulmifolia Lam., Parnaíba, Piauí.

\begin{tabular}{|c|c|c|c|c|c|}
\hline FRUTOS & MÁXIMO & MÉDIA & MÍNIMO & DP & $\mathrm{CV} \%$ \\
\hline Comprimento (mm) & 19,39 & 17,51 & 14,95 & $\pm 2,138$ & 12,21 \\
\hline Largura (mm) & 21,43 & 18,28 & 15,75 & $\pm 2,610$ & 14,27 \\
\hline Massa (g) & 3,24 & 2,29 & 1,33 & $\pm 0,718$ & 31,35 \\
\hline \multicolumn{6}{|l|}{ SEMENTES } \\
\hline $\mathrm{N}^{\mathrm{o}}$ de sementes por fruto & 100 & 63 & 27 & $\pm 31,06$ & 48,75 \\
\hline Comprimento (mm) & 2,90 & 2,55 & 2,02 & $\pm 0,301$ & 11,81 \\
\hline Largura (mm) & 1,97 & 1,71 & 1,36 & $\pm 0,233$ & 13,65 \\
\hline Massa (g) & 0,0052 & 0,0047 & 0,0043 & $\pm 0,00037$ & 6,38 \\
\hline
\end{tabular}

DP = Desvio Padrão/ CV = Coeficiente de Variação/ Fonte: Autores. 
Com relação à frequência das dimensões mensuradas nos frutos de Guazuma ulmifolia, verificou-se que a maior parte destes possui de 17,9 a 16,9 mm de comprimento, 19,4 a 18,4 mm de largura e 2,2 a 1,7 g por unidade (Figura 2A-C). Na frequência das dimensões mensuradas nas sementes da espécie, verificou-se que a maior parte das sementes possui de 2,7 a 2,5 mm de comprimento, 1,8 a 1,7 mm de largura e 0,0048 a 0,0046 g por unidade (Figura 2D-F).

Figura 2. Frequência de comprimento (A), largura (B) e massa (C) para uma amostra de 100 frutos e; comprimento (D), largura (E) e massa (F) para uma amostra de 100 sementes de Guazuma ulmifolia, Parnaíba, Piauí.

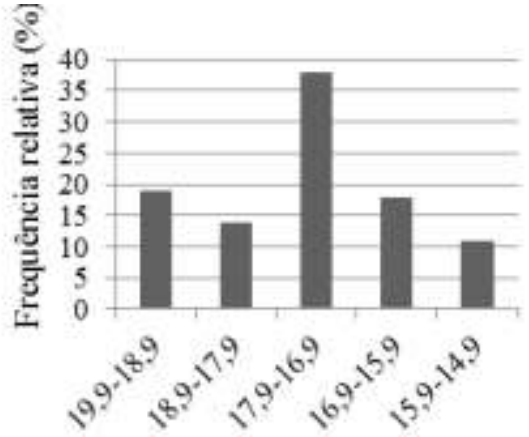

Comprimento dos frutos (mm)

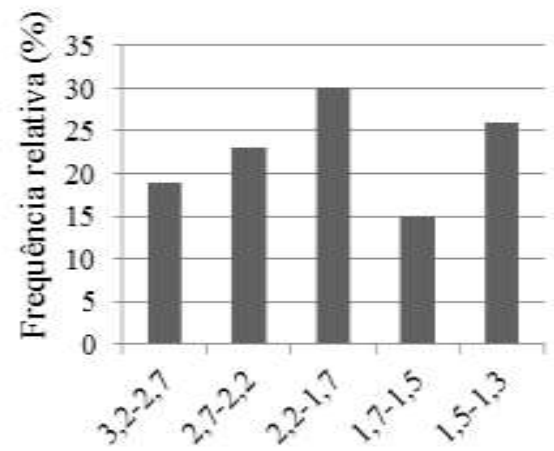

Massa dos frutos $(\mathrm{g})$

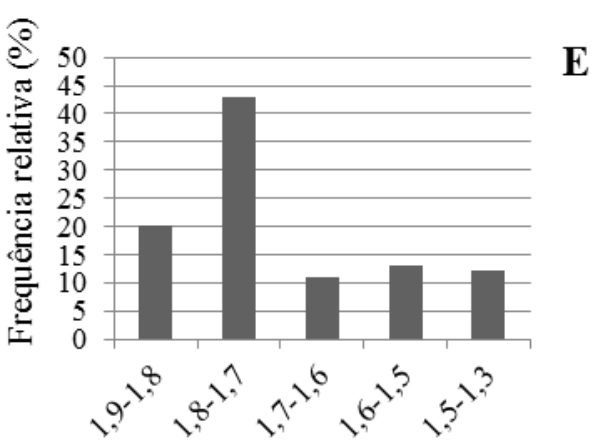

Largura das sementes ( $\mathrm{mm})$

A

C

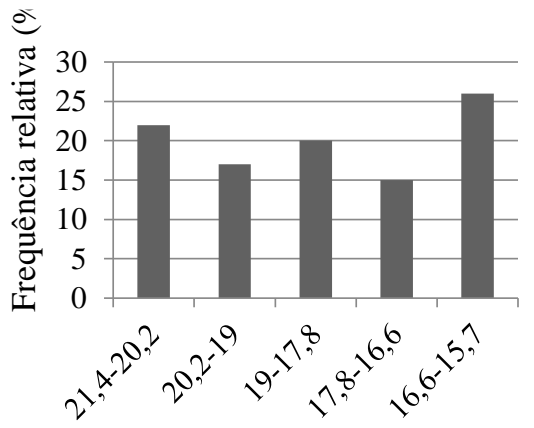

B

Largura dos frutos (mm)

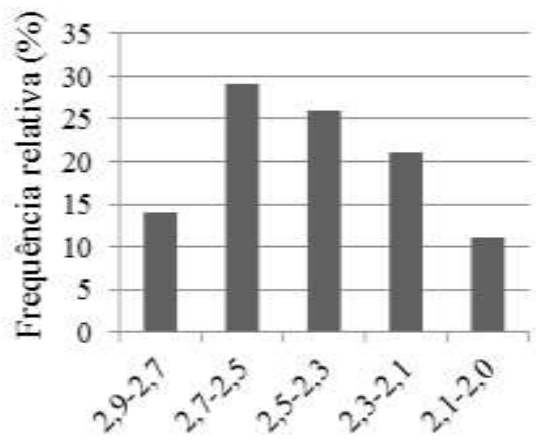

D

Comprimento das sementes (mm)

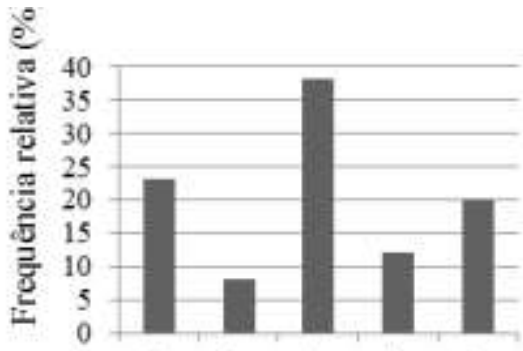

F 
As sementes de Guazuma ulmifolia apresentaram grau de umidade inicial de 6,97\%, e número de sementes por quilograma com média de 271.391. Kuhlmann (2012) caracterizou esta espécie com teor de água inicial de 3\%, sendo um pouco abaixo do encontrado no presente estudo.

De acordo com Catie (1997), as sementes podem ser armazenadas com grau de umidade de 6 a $7 \%$ em contentores selados sob temperaturas de $5^{\circ} \mathrm{C}$. Essas condições permitem manter a viabilidade dessas sementes por vários anos (Arriaga, Cervantes \& Vargas-Mena, 1994). Lima, Green, Zeviani, Lopes e Rios (2017), apontam que o grau de umidade afeta a germinação e o vigor das sementes. Entretanto, neste estudo, o grau de umidade não apresentou influência negativa sobre a germinação, tendo em vista que os resultados foram satisfatórios.

Neste estudo, na determinação do peso de 1.000 sementes obteve-se uma média 4,6g para cada 1.000 sementes. Dado semelhante também foi registrado por Araújo et al. (2016) em sementes de Theobroma cacao L. Os dados de características físicas e teor de água inicial das sementes encontram-se na Tabela 2.

Tabela 2. Características físicas de sementes de Guazuma ulmifolia Lam., Parnaíba, 2019.

\begin{tabular}{cc}
\hline CARACTERÍSTICAS FÍSICAS & RESULTADOS \\
\hline Grau de umidade $(\%)$ & $6,97 \%$ \\
Peso de 1.000 sementes & $4,6 \mathrm{~g}$ \\
Número de sementes por quilo & 217.391 \\
\hline
\end{tabular}

Fonte: Autores.

\subsection{Biometria da plântula}

Vinte e quatro horas após a semeadura, as sementes apresentaram-se entumecidas e com coloração mais escura, sendo possível verificar o início da abertura do tegumento. A germinação desta espécie é descrita como epígea, e tem início com a abertura do tegumento e emissão da raiz primária (Figura 3A), no presente estudo os resultados indicaram que a mesma ocorreu dois dias após a semeadura. Na Figura 3B, verifica-se que a raiz primária apresenta pelos de coloração branca, com curvatura acentuada no início com crescimento linear e constante (Figura 3C) e formação dos primeiros folíolos (Figura 3D).

No terceiro dia, para as sementes emergidas nos testes realizados com o ácido sulfúrico, as plântulas apresentaram os primeiros folíolos já formados. Com relação às sementes imersas em água quente e testemunha, verificou-se a formação dos primeiros folíolos no quinto dia de observação. Entretanto, a protrusão da radícula também ocorreu no segundo dia após a semeadura. Os resultados obtidos divergem daqueles descritos por Sobrinho, Siqueira, Morais e Silva (2012), em que para essa mesma espécie a germinação da testemunha foi observada 60 dias após a semeadura.

O desenvolvimento da plântula se estendeu de três a cinco dias após a protrusão da radícula, de acordo com cada tratamento. A biometria se iniciou no terceiro dia de semeadura logo após o momento em que a radícula ultrapassa o tegumento e se estendeu até o sexto dia quando os primeiros folíolos já estavam completamente formados. Durante o período de desenvolvimento foram encontrados os valores de comprimento de 2,44; 4,65; 17,98 e 18,60 mm, respectivamente, para cada dia de desenvolvimento da plântula. 
Figura 3. Aspectos morfológicos do desenvolvimento da plântula. (A) protrusão da radícula; (B): raiz primária; (C): cinco dias após a semeadura; D: sete dias após a semeadura.

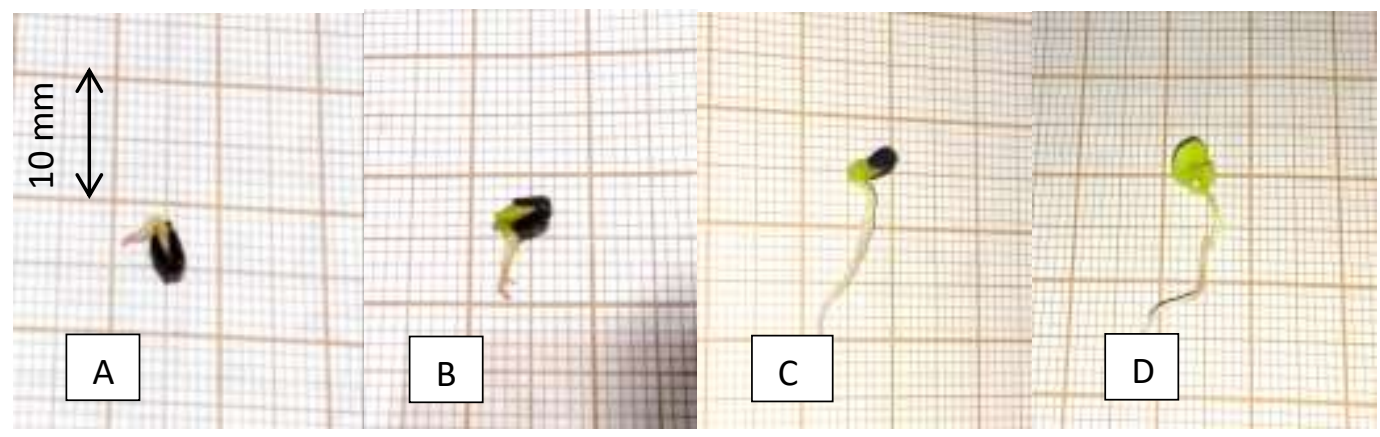

Fonte: Autores.

\subsection{Superação da dormência}

Pelos resultados da análise de variância do \%G (Tabela 3), observou-se que a imersão em água quente a $90^{\circ} \mathrm{C}$ por 10 minutos foi o tratamento mais eficiente na superação da dormência de sementes de Guazuma ulmifolia, proporcionando $68 \%$ de emergência. De acordo com Filho et al. (2019) a dormência das sementes dessa espécie pode ser superada quando submetidas a temperatura de $60^{\circ} \mathrm{C}$ por 16 minutos. Os demais tratamentos não aumentaram significativamente a germinação, igualando-se à testemunha. Para a análise de variância do TME, observou-se que não houve diferença significativa.

No que se refere ao método de tratamento de imersão em água quente (Marchiori, Fidelis, Kozovits \& Garcia, 2015), obtiveram maior taxa de germinação quando colocaram sementes de Vernonia flexuosa Sims em água com temperatura a $60^{\circ} \mathrm{C}$. Já Pazuch et al. (2014), não obtiveram êxito utilizando água quente na superação da dormência de Ipomoea purpurea (L.) Roth.

Tabela 3. G\%, IVE e TME de Guazuma ulmifolia submetidas a diferentes tratamentos para a superação de dormência. Parnaíba, 2019.

\begin{tabular}{cccc}
\hline TRATAMENTOS & $\% \mathrm{G}$ & IVE & TME \\
\hline Testemunha & $12,0 \mathrm{~b}$ & $0,91 \mathrm{~b}$ & $3,41 \mathrm{ab}$ \\
Imersão em H2SO4/5min. & $10,0 \mathrm{~b}$ & $0,95 \mathrm{~b}$ & $2,28 \mathrm{ab}$ \\
Imersão em H2SO4/15min. & $9,0 \mathrm{~b}$ & $0,89 \mathrm{~b}$ & $2,81 \mathrm{ab}$ \\
Imersão em H2SO4/30min. & $8,0 \mathrm{~b}$ & $0,73 \mathrm{~b}$ & $3,16 \mathrm{ab}$ \\
Imersão em H2SO4/50min. & $9,0 \mathrm{~b}$ & $1,08 \mathrm{~b}$ & $1,55^{\mathrm{a}}$ \\
Imersão em H-S(=O)2-OH/50 min & $7,0 \mathrm{~b}$ & $0,58 \mathrm{~b}$ & $3,00 \mathrm{ab}$ \\
Imersão em H-S(=O)2-OH/60 min & $10,0 \mathrm{~b}$ & $0,83 \mathrm{~b}$ & $2,25 \mathrm{ab}$ \\
Imersão em HCl/60 min & $9,0 \mathrm{~b}$ & $0,75 \mathrm{~b}$ & $3,06 \mathrm{ab}$ \\
Imersão em água quente & $68,0 \mathrm{a}$ & $4,48 \mathrm{a}$ & $6,12 \mathrm{~b}$ \\
\hline Valor de F & 15.697 & 9.303 & 2.415 \\
DMS & 23,825 & 1,92 & 53.63 \\
\hline
\end{tabular}

* Letras iguais não diferem estatisticamente pelo teste Tukey a $5 \%$ de probabilidade DMS- Desvio Médio Padrão; CV- Coeficiente de Variação.

Valor de F = Variação entre médias da amostra/Variação dentro das amostras. Fonte: Autores. 
A escarificação química com ácido sulfúrico a $98 \%$ por 50 minutos foi ineficiente na superação da dormência das sementes, tendo uma porcentagem de germinação de apenas 9\%. Por outro lado, Sales et al. (2018), constataram que a imersão em ácido sulfúrico a $98 \%$ por 50 minutos foi o método mais eficiente.

Já para as sementes imersas por 5, 15 e 30 minutos em ácido sulfúrico, os tratamentos também não foram eficientes na superação da dormência tegumentar, tendo uma porcentagem de germinação de 10\%, 9\% e 8\%, respectivamente (Tabela 3). Porém, esse método apresenta eficiência para outras espécies florestais como, por exemplo, Stizolobium aterrimum Piper \& Tracy, verificada por Oliveira, Silva e Alves (2017) a qual, quando submetida à três tempos de imersão, acelerou e sincronizou a emergência das plântulas.

Embora o uso do método de imersão das sementes em ácido sulfúrico, independente do tempo, para a superação da dormência tenha sido ineficiente neste estudo, outros autores, como Sales et al. (2018), classificaram-no como o método mais eficiente na superação de dormência desta espécie, a exemplos de Filho, Nunes, Costa, Nogueira e Costa (2011) e de Ferreira, Carvalho e Reis (2014) os quais observaram que os maiores índices de germinação nas sementes ocorreram ao serem expostas ao ácido por 50 minutos.

Os tratamentos T6, T7 e T8 também não mostraram resultados positivos quanto aos testes, apresentando uma taxa de emergência inferior à testemunha, a qual obteve uma porcentagem de germinação de $12 \%$. A baixa germinação obtida indica que os períodos de imersão, provavelmente, foram insuficientes para promover a escarificação completa do tegumento, não permitindo a entrada de água e contato direto com o embrião, outra provável causa pode ser atribuída a danos fisiológicos à a estrutura interna das sementes (Tabela 3). Resultados semelhantes foram encontrados por Vela, Moterle, Santos, Chichanoski e Braccini (2018), ao que não observaram êxito nos tratamentos para superar a dormência de Brachiaria brizantha (Hochst. ex A. Rich.) Stapf., relatando germinação superior em sementes não tratadas.

\section{Considerações Finais}

Os frutos de Guazuma ulmifolia Lam. apresentam variação no que se refere às características biométricas, com maiores registros no comprimento, enquanto que para as sementes as características homogêneas e constantes, não apresentaram variações em nenhum dos aspectos observados. Quanto à análise biométrica das plântulas, estas obtiveram crescimento linear e constante durante o período de observação.

Em relação ao peso e ao tamanho das sementes, os mesmos estão diretamente interligados à sua qualidade fisiológica. $\mathrm{O}$ tratamento de imersão em água quente a $90^{\circ} \mathrm{C}$ por 10 minutos foi eficiente para superar a dormência em sementes de Guazuma ulmifolia, proporcionando uma taxa de germinação de $68 \%$. Estudos que a abordam a superação da dormência em sementes florestais são primordiais, principalmente para agricultores que visam a produção de mudas. Tais tratamentos podem auxiliar na padronização e uniformidade na produção de mudas vegetais.

\section{Referências}

Araújo, E. L., Nunes, J. R., Posse, S. C. P., Neto, B. C., Santos, M. F., Crasque, J., Souza, C. A. S., \& Arantes, S. D. (2016). Obtenção de peso de mil sementes em genótipos de cacaueiro (Theobroma cacao L.). I SICT do Incaper.

Araújo, L. S., Lima, G. A., \& Lemos, J. R. (2019). Floristic, phytosociology and economic potential of plant species from a section of vegetation in the North

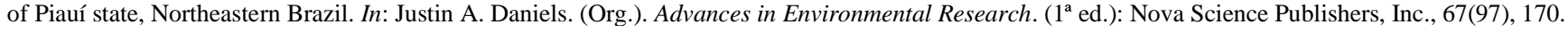

Arriaga, V., Cervantes, V., \& Vargas-Mena, A. (1994). Manual de Reforestación con Especies Nativas: Colecta y Preservación de Semillas, Propagación y Manejo de Plantas. Ciudad de México: SEDESOL / INE - Facultad de Ciencias UNAM, 219.

Banzatto, D. A., \& Kronka, S. N. (1992) Experimentação Agrícola. (2a ed.), FUNEP, 2 b46.

Barbosa, J. M., \& Macedo, A. C. (1993). Essências florestais nativas de ocorrência no Estado de São Paulo: informações técnicas sobre sementes, grupo ecológico, fenologia e produção de mudas. São Paulo: Instituto de Botânica e Fundação Florestal, 125. 
Batista, G. S., Costa, R. S., Gimenes, R., Pivetta, K. F. L., \& Môro, F. V. (2011). Aspectos morfológicos dos diásporos e das plântulas de Syagrus oleracea (Mart.) Becc - Arecaceae. Comunicata Scientiae, 2(3), 170-176.

Bewley, J. D., Bradford, K., \& Hilhorst, H. (2013). Seeds: physiology of development, germination and dormancy. (3a ed.), Springer.

Bílio, R. S. (2018). Fenologia, germinabilidade e qualidade de sementes de Alibertia edulis Rich. E Lafoensia pacari St. Hill. (Programa de Pós-graduação em Agricultura Tropical), Universidade Federal de Mato Grosso.

Brasil. (1992). Ministério da Agricultura e Reforma Agrária. Regras para análise de sementes: SNDA/DNDV/CLAV. 365.

Brasil. (2009). Ministério da Agricultura, Pecuária e Abastecimento. Regras para análise de sementes: Mapa/ACS. 399.

Candido, D. F., \& Oliveira, A. S. (2018). Métodos para a superação da dormência em sementes de Schizolobium parahyba (Vellozo) S. F. Blake (Fabaceae). Acta Biológica Catarinense, 5(2), 98-105.

Carvalho, N. M., \& Nakagawa, J. (2012). Sementes: ciência, tecnologia e produção. (5a ed.) Jaboticabal: FUNEP. 590.

Carvalho, P. E. (2007). Mutamba (Guazuma ulmifolia), Taxonomia e nomenclatura. In: Circular Técnica Embrapa, 141. Colombo. 13.

Catie. (1997). Centro agronômico tropical de investigación y enseñanza. Guazuma ulmifolia Lam. in: nota técnica sobre manejo de semillas forestales, Turrialba, 7.

Chaves, I. S., Silva, N. C. Q., \& Ribeiro, D. M. (2017). Effect of seed coat on dormancy and germination in Stylosanthes humilis H. B. K. seeds. Journal of Seed Science, 39, 114-122.

Fernandes, T. S., Nunes, U. R., Filho, A. C., Fagundes, L. K., Dalcin, J. S., \& Ludwig, E. J. (2018). Contribuição para a uniformização de metodologias de análise de germinação e vigor de sementes de soja. Revista de Ciências Agrárias, 41(1), 121- 13.

Ferreira, D. F. (2000). Análise estatística por meio do SISVAR (Sistema para Análise de Variância) para Windows versão 4.0. In: Reunião anual da região brasileira da sociedade internacional de biometria, 45. São Carlos. Anais: UFSCar, 255-258.

Ferreira, M. G., Carvalho, J. C., \& Reis, A. R. S. (2014). Método de quebra de dormência e germinação de samaúra brava (Cochlospermum orinocense (Kunth) Steud.) e a mutamba (Guazuma ulmifolia Lam.). Enciclopédia Biosfera, Centro Científico Conhecer - Goiânia, 10(18).

Figliolia, M. B. (2015). A pesquisa e o estabelecimento de técnicas para análise de sementes florestais no Brasil. In: Piña-Rodrigues, F. C. M., Figliolia, M. B., \& Silva, A. Sementes Florestais Tropicais: da ecologia à produção. Londrina: Abrates, 286-288.

Filho, J. G., Mendes, R. G., Fialho, F., Piva, H. T., Rezende, A. R., Vargas, B. C., Neto, J. A. D., \& Hipólito, A. N. (2019). Superação de dormência e uso de bioestimulante na germinação de diásporos mutamba. Braz. J. of Develop, Curitiba, 5(10), 17429-17445.

Filho, J. H. C., Nunes, G. H. S., Costa, G. G., Nogueira, C. S. R., \& Costa, M. R. (2011). Superação de dormência em sementes de mutamba (Guazuma ulmifolia LAM.). Revista Verde (Mossoró - RN - Brasil), 6(2), 193 - 200.

Gonçalves, A. F. A., Carvalho, L. R., \& Cabacinha, C. D. (2017). Biometria de frutos, armazenamento e germinação de sementes de Stryphnodendron adstringens (Mart.) Coville. Caderno de Ciências Agrárias, 9(3), 38-48.

Grzybowski, C. R. S., Silva, R.C., Belniaki, A. C A., \& Panobianco, M. (2019). Investigation of dormancy and storage potential of seeds of yellow passion fruit. Journal of Seed Science, 41(3), 367-374.

Kuhlmann, M. (2012). Frutos e sementes do Cerrado atrativos para fauna: guia de campo. Marcelo Kuhlmann; colaborador Christopher Fagg. Brasília, Ed. Rede de sementes do Cerrado.

Labouriau, L. G. (1983). A germinação das sementes. Washington: Secretaria Geral da Organização dos Estados Americanos. 174.

Labouriau, L. G., \& Valadares, M. E. B. (1976). On the germination of seeds Calotropis procera (Ait.). Anais da Academia Brasileira de Ciências, 48(2), 263284.

Leão, N. V. M., Shimizu, E. S. C., Felipe, S. H. S., Benchimol, R. L., \& Nascimento, M. R. S. M. (2018). Morfometria, germinação e sanidade de sementes de tachipeludo. Enciclopédia biosfera, Centro Científico Conhecer - Goiânia, 15(27).

Lima, W. A. A., Green, M. Zeviani, W. M., Lopes, R., \& Rios, S. A. (2017). Teor de água e tempo de exposição ao tratamento térmico na germinação de sementes de caiaué. Revista de Ciências Agrárias/Amazonian Journal of Agricultural and Environmental Sciences, 60(2), 192-198.

Lorenzi, H. (2016). Árvores brasileiras Volume 1: Manual de identificação e cultivo de plantas arbóreas nativas do Brasil. (7a ed.) Nova Odessa, SP: Editora Plantarum, 384

Maguire, J. D. (1962). Speed of germination aid in selection and evaluation for seedling emergence and vigor. Crop Science, 2(2), 176-177.

Marchiori, N. M., Fidelis, A. T., Kozovits, A. R., \& Garcia, Q. S. (2015). Germinação de sementes nativas dos campos sulinos após armazenamento e choque de temperatura. Revista Biociências, 21(1), 89-99.

Marcos-Filho, J. (2015). Fisiologia de sementes de plantas cultivadas: ABRATES. 659.

Mendes, C. S., Costa, F. N., Lima, L. S. A., Carvalho, J. C., \& Reis, A. R. S. Superação de dormência em sementes de jutaí-mirim (Hymenaea parvifolia Huber). Biota Amazônia, 6, 12-16. 
Mendonça, A. V. R., Freitas, T. A. S., Souza, L. S., Fonseca, M. D. S., \& Souza, J. S. (2016). Morfologia de frutos e sementes e germinação de Poincianella pyramidalis (Tul.) L. P. Queiroz, comb. Nov. Ciência Florestal, Santa Maria, 26(2), 375-387.

Mews, C. L., Silvério D. V., Mews, H. A., Cury. R., \& Santos, T. (2012). Efeito do substrato e de diferentes tratamentos pré-germinativos na germinação de sementes de Tento - Ormosia paraensis Ducke (Fabaceae). Revista Biotemas, 25(1), 11-16.

Naves, V. L., \& Rezende, R. M., Alcantra, L., \& Rezende, R. A. L. (2018). Superação da dormência em sementes de olho-de-cabra (Ormosia arborea) por diferentes métodos. Revista da Universidade Vale do Rio Verde, 16(3), Edição Especial, 1.

Oliveira, J. D., Silva, J. B., \& Alves, C. Z. (2017). Tratamentos para incrementar, acelerar e sincronizar a emergência de plântulas de mucuna-preta. Revista Ciência Agronômica, 48(3), 531-539.

Oliveira, S. S. C., Filho, C. P. C., Sousa, L. R., \& Cruz, S. J. S. (2018). Caracterização morfométrica de sementes, frutos e plântulas e germinação de sementes de Physocalymma scaberrimum Pohl. Revista de Ciências Agrárias.

Pazuch, D., Trezzi, M. M., Diese, F., Barancelli, M. V. J., Batiste, C., \& Pasini, R. (2014). Superação de dormência em sementes de três espécies de Ipomoea. Ciência Rural, Santa Maria, Online.

Pereira A. S., Shitsuka, D. M., Pereira, F. J., \& Shitsuka, R. (2018). Metodologia da pesquisa científica. UFSM. Pereira, M. D., Filho, S. M., \& Laviola, B. G. (2012). Envelhecimento acelerado de sementes de pinhão-manso. Pesquisa Agropecuária Tropical, 42(1), $119-123$.

Pernambuco. (2013). Parque Estadual Mata da Pimenteira: plano de manejo. Secretaria de Meio Ambiente e Sustentabilidade, Agência Estadual de Meio Ambiente. Recife, PE, 90

Ramos, K. M. O. (2015). Caracterização da qualidade fisiológica e otimização do processo de ozonização em sementes de leguminosas arbóreas do Cerrado. 146 f. (Tese Doutorado em Ciências Florestais) - Universidade de Brasília, Brasília.

Reis, A. R., Freitas, A. D. D. F., Leão, N. V. M., \& Santos Filho, B. G. (2016). Morphological aspects of fruits, seeds, and seedlings, and anatomy of seedlings of Apuleia molaris spruce ex benth. Journal of Seed Science, 38(2), 118-128.

Sales, N. L., Cota, C. G., Freitas, F. G. R., Moreira, J. L., Carvalho, L. R., Moreira, C. D., \& Barroso, P. D. (2018). Germinação, sanidade e tratamento de sementes de Guazuma ulmifolia Lam. Caderno de Ciências Agrárias,10(2), 46-52.

Sampaio, M. F., Couto, S. R., Silva, C. A., Silva, A. C. A., Silva, A. A. S., \& Teixeira, A. L. (2015) Influência de diferentes substratos associados a métodos de superação de dormência na germinação e emergência de sementes de Jatobá (Hymenaea courbaril L.). Revista Farociência, 2(1).

Santana, B. J. G., Silva, J. P. G., Morangon, L. C., \& Feliciano, A. L. P. (2018). Morfologia externa de sementes e plântulas de Parkia pendula Benth. ex Walp. Arrudea 4, 2-10.

Santos, D. G. J., Deuner, C., Meneghello, G. E., Almeida, A. P. F., \& Xavier, F. M. (2016). Superação de dormência em sementes de pau de balsa (Ochroma pyramidale). Revista Verde, 11, 18-22.

Silva, E. A., Teixeira, M. C. S. A., Mendes, M. R. A., Lemos, J. R., \& Freitas, R. N. (2019). Análises físicas e morfológicas de Canavalia dictyota Piper (Fabaceae). Enciclopédia biosfera, Centro Científico Conhecer - Goiânia, 16(29).

Silva, E. M. S., Bispo, R. B., Pedri, E. C. M., Lopes, C. R. A. S., \& Rossi, A. A. B. (2017). Morfometria de frutos e sementes de Palicourea racemosa em um fragmento florestal na região norte de mato grosso, Brasil. Enciclopédia biosfera, Centro Científico Conhecer - Goiânia, 14(26).

Silva, F. W. A., Gurgel, E. S. C., Cruz, E. D., \& Santos, J. U. M. (2016). Morfologia do fruto, da semente, da plântula e da planta jovem de Sarcaulus brasiliensis A. DC. Eyma (Sapotaceae). Biota Amazônia, Macapá, 6(3), 7-11.

Soares, I. D., Nogueira, A. C., Grabias, J., \& Kuniyoshi, S. (2017). Caracterização morfológica de fruto, semente e plântula de Psidium rufum DC. (Myrtaceae). Iheringia, Série Botânica, 72(2), 221-227.

Sobrinho, S. P., \& Siqueira, A. G. (2008). Caracterização morfológica de frutos, sementes e plântulas jovens de (Guazuma ulmifolia Lam. - Sterculiaceae). Revista Brasileira de Sementes, 30(1), 114-120.

Sobrinho, S. P., Siqueira, A. G., Morais, P. B., \& Silva, S. J. P. (2012). Superação da dormência em sementes mutamba (Guazuma ulmifolia Lam. Sterculiaceae). Revista Árvore, Viçosa-MG, 36(5), 797-802.

Souza, V. C., \& Lorenzi, H. (2019). Botânica sistemática: guia ilustrado para identificação das famílias de fanerógamas nativas e exóticas no Brasil, baseado em APG IV. (4a ed.): Instituto Plantarum, 768.

Vela, R. S., Moterle, L. M., Santos, R. F., Chichanoski, C., \& Braccini, A. L. (2018). Quebra de dormência em sementes de Brachiaria brizantha (Hochst.ex A. Rich.) Stapf. Revista de Ciências Agrárias, 41(2), 327-335-327.

Zapater, M. A., Hoc, P. S., Flores, C. B., Mamani, C. M., Lozano, E. C., \& Suhring, S. S. (2016). Chloroleucon tenuiflorum (Leguminosae, Ingeae): Morphometry of Fruits, Seeds and Seedlings, Healthy and Germinability. Global Journal of Biology, Agriculture \& Health Sciences, 5(3), 95-106. 